Discussion Paper No. 08-104

\title{
Which is the Right Dose of EU Cohesion Policy for Economic Growth?
}

Tobias Hagen and Philipp Mohl

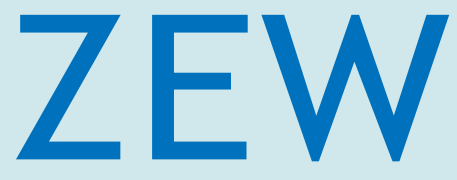

Zentrum für Europäische Wirtschaftsforschung $\mathrm{GmbH}$

Centre for European

Economic Research 
Discussion Paper No. 08-104

\title{
Which is the Right Dose of EU Cohesion Policy for Economic Growth?
}

\author{
Tobias Hagen and Philipp Mohl
}

Download this ZEW Discussion Paper from our ftp server:

ftp://ftp.zew.de/pub/zew-docs/dp/dp08104.pdf

Die Discussion Papers dienen einer möglichst schnellen Verbreitung von neueren Forschungsarbeiten des ZEW. Die Beiträge liegen in alleiniger Verantwortung der Autoren und stellen nicht notwendigerweise die Meinung des ZEW dar.

Discussion Papers are intended to make results of ZEW research promptly available to other economists in order to encourage discussion and suggestions for revisions. The authors are solely responsible for the contents which do not necessarily represent the opinion of the ZEW. 


\section{Non-technical summary}

The European Cohesion Policy aims at promoting economic and social cohesion by reducing the gap between the development levels of the various regions. The ultimate goal is to reach a convergence of regional GDP per capita. This is to be achieved through payments from the so-called "European structural funds"; payments which are nationally co-financed.

The econometric investigation of the impact of European Cohesion Policy on economic growth and/or convergence has been intensified over the last decade. However, the empirical results are not clear-cut. While some authors find evidence of a significant positive impact of structural funds on economic growth, others only find a weak impact, or none at all. There are several reasons for these mixed results, among others, the low quality of structural funds data (at the regional level) and a number of methodological problems.

Against this background, this paper analyses the growth effects of EU structural funds by applying a relatively new econometric approach (the socalled "generalized propensity score"), which takes into account one of the methodological problems. More precisely, this method avoids functional form assumptions on the relationship between structural funds payments and economic growth to a large extent. Thus, we are able to reach results which are more robust with regard to this issue. Our method employs a new panel dataset of 122 NUTS-1 / NUTS-2 regions over the time period 1995-2005. Hence, in contrast to other studies, we extend the time period of investigation, using structural funds payments of the last Financial Perspective 2000-2006.

Our results indicate that structural funds payments have a positive, but not statistically significant, impact on the European regions' growth rates. This implies that it does not matter which "dose" of SF payments a region receives. 


\section{Zusammenfassung}

Das Ziel der europäischen Kohäsionspolitik besteht darin, den wirtschaftlichen und sozialen Zusammenhalt innerhalb der EU zu stärken, indem die Entwicklungsunterschiede in den verschiedenen Regionen verringert werden sollen. Dabei wird eine Konvergenz der regionalen pro-Kopf Bruttoinlandsprodukte angestrebt. Hierzu werden Zahlungen aus den sogenannten europäischen Strukturfonds zur Förderung von Projekten geleistet, welche von den Mitgliedstaaten kofinanziert werden müssen.

Die Anzahl an empirischen Studien, welche die Wachstums- bzw. Konvergenzeffekte von Strukturfondszahlungen analysieren, hat in der Vergangenheit zugenommen. Allerdings sind die Ergebnisse nicht eindeutig: Während einige Autoren Evidenz für einen signifikant positiven Einfluss der Strukturfonds auf das Wirtschaftswachstum finden, können andere Autoren nur schwache oder keine Evidenz für einen solchen Zusammenhang nachweisen. Diese divergierenden Ergebnisse lassen sich unter anderem mit der schlechten Datenqualität (auf regionaler Ebene) sowie einer Reihe methodischer Probleme erklären.

Vor diesem Hintergrund werden in dieser Studie die Wachstumseffekte der Europäischen Strukturfonds untersucht, wobei ein relativ neuer ökonometrischer Ansatz verwendet wird (der sogenannte "Generalisierte Propensity Score"), der eines der methodischen Probleme berücksichtigt. Hierbei werden Annahmen bezüglich der funktionalen Form des Zusammenhangs zwischen Strukturfondszahlungen und Wirtschaftswachstum weitgehend vermieden, so dass diesbezüglich robustere Ergebnisse erzielt werden. Wir verwenden einen Datensatz basierend auf 122 NUTS-1 / NUTS-2 Regionen für die Periode 1995 bis 2005, womit der Untersuchungshorizont auf Strukturfondszahlungen aus der Finanziellen Vorausschau 2000 bis 2006 aus-gedehnt wird.

Die empirischen Ergebnisse deuten darauf hin, dass zwar ein positiver Kausalzusammenhang zwischen Strukturfondszahlungen und Wirtschaftswachstum besteht, dass dieser jedoch nicht statistisch von Null verschieden ist. Dieses Ergebnis impliziert, dass es bezüglich der Wachstumseffekte irrelevant ist wie hoch die Strukturfondszahlungen sind, die an eine Region fließen. 


\title{
Which is the Right Dose of EU Cohesion Policy for Economic Growth?
}

\author{
Tobias Hagen ${ }^{\star \star}$ and Philipp Mohl
}

December 6, 2008

\begin{abstract}
The current empirical literature on the impact of EU Cohesion Policy on the economic growth rates of the European regions mainly relies on functional form assumptions. However, it is ex ante not clear which functional form is appropriate with regard to the relationship between structural funds payments and regional economic growth. In order to avoid such assumptions, this paper applies the method of generalized propensity score (GPS) to a sample of 122 NUTS-1 and NUTS-2 EU-15 regions for the time period 19952005 , which leads to the estimation of a dose-response function, as proposed by Hirano and Imbens (2004).

Our results indicate that structural funds payments have a positive, but not statistically significant, impact on the regions' average three-year growth rates. This implies that it does not matter which "dose" of structural funds payments a region receives.
\end{abstract}

Keywords: EU structural funds, economic growth, continuous treatment, dose-response function

JEL classification: C21, I38, R11

$\star \star$ Professor, University of Applied Labour Studies (Hochschule der Bundesagentur für Arbeit), Seckenheimer Landstraße 16, 68163 Mannheim, Germany, E-mail: tobiashagen@ email.de

* Research Fellow; Centre for European Economic Research (ZEW) and University of Heidelberg, P.O. Box 103443, 68034 Mannheim, Germany, E-mail: mohl@zew.de 


\section{Introduction}

A large part of the EU budget is spent on so-called "Cohesion Policy" via the structural funds (SF). Its main goal is to reduce disparities between the development levels and to foster regional economic and social cohesion (Art. 158 TEC). Surprisingly, despite an extensive literature on the impact of Cohesion Policy on economic growth, the empirical evidence has not delivered clear-cut results. While some authors do find evidence of a positive impact of SF on economic growth (Beugelsdijk and Eijffinger, 2005), others find only conditionally-positive effects (Bähr, 2008; Ederveen, de Groot, and Nahuis, 2006), and some find no positive impact at all (see Dall'erba and Le Gallo, 2008). These mixed results can be explained, inter alia, by the low quality of SF data at the regional level, differences in the choice and the timing of the sample and a number of methodological problems.

One drawback of the current literature is that it relies on functional form assumptions. Although growth theory provides well-established suggestions for the estimation of growth relationships (see, among others Islam, 2003; Durlauf and Quah, 1999), it is ex ante not clear which functional form is appropriate for the relationship between SF payments and economic growth. In particular, there may be non-linearities and interactions with covariates, which may lead to biased estimates if they are not taken into account.

Against this background, we try to avoid simple functional form assumptions by interpreting SF payments as a continuous treatment and by using the method of generalized propensity score (GPS), as proposed by Hirano and Imbens (2004) and further developed by Moodie and Stephens (2007). This method is applied using a panel data-set of 122 NUTS-1 / NUTS-2 regions for the time period 1995-2005 in order to explain the effect of SF payments on the growth rate of average three-year real GDP. To the best of our knowledge, this dataset has only been analyzed by Mohl and Hagen (2008) as yet, and it is the only dataset that includes SF payments of the Financial Perspective 2000-2006. The results indicate that SF payments have a positive, but not statistically significant, impact on the regions' average three-year growth rates. 
This paper is structured as follows: Section 2 discusses the main methodological difficulties in the context of the empirical literature on EU Cohesion Policy and growth. Section 3 focuses on the implementation of the method of GPS. Section 4 describes the data used. This is followed by a presentation of the main results in Sections 5 and 6, and a conclusion in Section 7.

\section{Methodological Challenges}

The estimation of the relationship between SF payments and the regions' growth rates is complicated by the potential endogeneity problem, i.e. the fact that within a regression model the covariance between at least one of the explanatory variables (e.g., the SF variable) and the disturbance term is not equal to zero. This endogeneity may be attributed to several factors:

First, endogeneity may be caused by a measurement error. This problem is enforced by the data availability at the regional level. Our overall aim is to measure the impact of the specific share of the European Cohesion Policy that is ultimately spent on the region in the respective years. However, in the multi-annual Financial Frameworks, the European Commission determines so-called "commitments" which do not have to be equal to the final payments. For example, due to missing absorption capability, the commitments may not be entirely depleted, or may be called up with a delay of one or two years. For reasons of data availability, some authors only take the commitments into account, which, in turn, results in a measurement error. Given that this error is part of the disturbance term and that the latter is correlated with one of the explanatory variables, the estimated results are biased due to endogeneity.

Second, endogeneity may occur due to simultaneity, i.e., at least one of the explanatory variables is determined simultaneously along with the dependent variable. In our context, the allocation criteria of the SF are likely to be correlated with the dependent variable "economic growth" for the following reasons. First, the main allocation criterion is related to economic wealth: If the ratio of regional GDP (in PPP) to the EU-wide GDP is below 75 percent, the region is a so-called "Objective 1" region, implying that the 
region is eligible for the highest transfers relative to GDP. ${ }^{1}$ The effective payments by the Commission to the regions depend on the regions' abilities to initiate and to co-finance projects. This ability may be higher in times of higher economic growth rates, e.g., due to higher tax revenues.

Third, endogeneity might result from an omitted variable bias, e.g., there may be observed variables that are not included in the specification or there may be unobserved variables, making these variables part of the error term. If these variables are constant over time, they can be eliminated by fixed-effects or by taking differences over time. However, if they are not constant, they might be correlated with one of the explanatory variables, once again leading to biased results. For example, there may be spillovers between regions which are not controlled: SF payments may increase the region's growth rate which, in turn, may positively affect the growth rates of the neighboring regions. If these spillovers are neglected, the estimated effect of SF payments might be biased.

Apart from these endogeneity-related aspects, the estimations might be biased by a fourth issue. Although growth theory provides well-established suggestions for the estimation of growth relationships (see, among others, Islam 2003), it is ex ante unclear which functional form is appropriate for the effect of SF payments. There may be non-linearities and interactions with covariates, which may lead to biased estimates if they are not taken into account. This issue has been neglected so far.

In the context of the investigation of SF payments and growth relationship, there are techniques to control for some of the mentioned difficulties, but not for all of them simultaneously. In order to mitigate the problem of measurement error, the following analysis concentrates on regional SF payments instead of commitments. As regards the problem of simultaneity, some authors (e.g., Esposti and Bussoletti, 2008; Mohl and Hagen, 2008; Hagen and Mohl, 2008; Percoco, 2005) use Generalized Method of Moments (GMM) estimators as proposed by Arellano and Bond (1991) or Blundell and Bond (1998). Moreover, some authors try to solve the problem of an omitted variable bias by explicitly taking into account regional spillover effects in a spatial

$1 \quad$ Furthermore, allocation depends, among others, on the regional unemployment rate, the employment structure, and the population density (see Section 5). 
regression framework (Dall'erba and Le Gallo, 2008; Mohl and Hagen, 2008).

However, the clear focus of this paper lies on the fourth problem that has, to the best of our knowledge, no yet been taken into account. As a consequence, we try to avoid simple functional form assumptions by interpreting SF payments as a continuous treatment and by applying the method of GPS as proposed by Hirano and Imbens (2004). This relatively new method is introduced in the subsequent section.

\section{Implementation of the Method of General- ized Propensity Score}

In the following, we interpret SF payments as a continuous treatment and make use of the method of GPS. So far, only few applied studies in economics using the GPS exist (see, for example Flores-Lagunes, Gonzalez, and Neuman, 2007; Kluve, Schneider, Uhlendorff, and Zhao, 2007; Fryges and Wagner, 2008; Bia and Mattei, 2007) and, to the best of our knowledge, there are no such studies in the field of regional economics. The aim of the method at hand is to estimate a dose-response function, representing the response (GDP growth rate) which is associated with different values of the continuous dose (SF payments). The terms "continuous treatment" and "dose" can be used synonymously.

A basic requirement of this model is the so-called "Stable Unit Treatment Value Assumption" (SUTVA; see Rubin, 1980) which claims that the distribution of the outcome for one unit (European region) is assumed to be independent of the potential treatment status of another unit, given the observed covariates (see Imai and van Dijk, 2004). Hence, interference between units, that is, spatial correlation, is ruled out (see the discussion in Section 2). Obviously, this assumption seems to be rather strong when the unit is a region. This implies that, e.g., given the covariates, SF payments in favor of Berlin do not affect growth in the region of Brandenburg, or that subsidies for the region of East of England do not affect growth in London. Moreover, recent econometric research (Dall'erba and Le Gallo, 2008; Mohl and Hagen, 2008) finds empirical evidence that cross-regional spillovers do 
matter. However, we are not able to control for spatial spillovers within our methodological approach. Instead, by applying a new method and by comparing the results to those in other papers using different techniques, we hope to obtain a general idea about the methodological problems and the range of the true effect of SF payments on growth.

The following brief explanation of the GPS method closely follows Hirano and Imbens (2004). ${ }^{2}$ Their key assumption is what they call the "weak unconfoundedness assumption". Let the treatment variable $S$ take on values in the interval $\mathbb{S}=\left[s_{0}, s_{1}\right]$. The assignment to treatment $(S)$ is weakly unconfounded, conditional on the pre-treatment covariates $X$, if

$$
Y(s) \perp S \mid X, \quad \text { for all } s \in \mathbb{S}
$$

with $Y(s)$ denoting the outcome (response) associated with the treatment level (dose) s. Equation (1) states that, conditional on the covariates $X$, the level of treatment received by a region is independent of the potential outcome $Y(s)$. This is also called exogeneity, unconfoundedness, or selection on observables (Imbens, 2004).

The GPS is defined as follows: If $r(s, x)$ is the conditional density of the treatment given the covariates $f_{S \mid X}(s \mid x)$, then the GPS is defined as $R=r(S, X)$. If the assignment to treatment is weakly unconfounded, Hirano and Imbens (2004) show that adjusting for the GPS eliminates the bias associated with differences in $X$. Hence, it is not necessary to condition directly on $X$ when estimating $Y(s)$. An important feature of the GPS is the so-called balancing property: The GPS "balances" the covariates, such that the probability that $S=s$ does not depend on the value of $X$. Finally, using the estimated GPS, a dose-response function representing the average potential outcome $E[Y(s)]$ over the whole range of the dose can be estimated.

In concrete terms, the method is implemented as described in Hirano and Imbens (2004) with the following three step procedure:

1. We estimate the GPS by OLS: Let $i$ denote one of $N$ regions. We use a normal distribution for the treatment conditional on the covariates

$2 \quad$ Further descriptions can be found in Flores-Lagunes, Gonzalez, and Neuman (2007), Kluve, Schneider, Uhlendorff, and Zhao (2007) as well as in Moodie and Stephens (2007). 
$S_{i} \mid X_{i} \sim N\left(\beta_{0}+\beta_{1}^{\prime} X_{i}, \sigma^{2}\right)$. The estimated GPS is calculated as:

$$
\hat{R}_{i}=\frac{1}{\sqrt{2 \pi \hat{\sigma}^{2}}} \exp \left(-\frac{1}{2 \hat{\sigma}^{2}}\left(S_{i}-\hat{\beta}_{0}+\hat{\beta}_{1}^{\prime} X_{i}\right)^{2}\right)
$$

2. The conditional expectation of $Y_{i}$ given $S_{i}$ and $R_{i}$ is modeled as a flexible function and the parameters $\left(\alpha_{0}, \ldots, \alpha_{5}\right)$ are estimated by OLS:

$$
\begin{aligned}
E\left[Y_{i} \mid S_{i}, R_{i}\right]= & \alpha_{0}+\alpha_{1} \cdot S_{i}+\alpha_{2} \cdot S_{i}^{2} \\
& +\alpha_{3} \cdot \hat{R}_{i}+\alpha_{4} \cdot \hat{R}_{i}^{2}+\alpha_{5} \cdot S_{i} \cdot \hat{R}_{i}
\end{aligned}
$$

3. Finally, the average potential outcome at treatment level $s$ is estimated as:

$$
\begin{aligned}
\widehat{E[Y(s)]}= & \frac{1}{N} \sum_{i=1}^{N}\left(\hat{\alpha}_{0}+\hat{\alpha}_{1} \cdot s+\hat{\alpha}_{2} \cdot s^{2}+\hat{\alpha}_{3} \cdot \hat{r}\left(s, X_{i}\right)\right. \\
& \left.+\hat{\alpha}_{4} \cdot \hat{r}\left(s, X_{i}\right)^{2}+\hat{\alpha}_{5} \cdot s \cdot \hat{r}\left(s, X_{i}\right)\right)
\end{aligned}
$$

The entire dose-response function is obtained by calculating this equation at each level of the treatment. The dose-response function shows how average responses vary along the interval of treatment doses. In our application, the treatment (or the dose) is defined as SF payments to a region in percent of the region's GDP. After having dropped seven observations with zero SF payments, we have 578 observations with nonmissing information on $X$ in 122 regions, implying $\mathbb{S}=[0.001 \%, 25.8 \%]$. Even though we estimate the propensity score on this sample, we restrict the calculation of the dose-response function on the range up to $3.4 \%$ (corresponding to the $75 \%$ quantile) in steps of 0.1 percentage points. The reason for doing this is the small number of observations (200) in the upper tail of the distribution of $\mathbb{S}$, which may lead to unreliable estimates.

From the estimated dose-response function it is also possible to calculate pairwise treatment effects of the following form (Flores, 2004):

$$
E\left(\Delta^{s_{1}, s_{2}}\right)=E\left[Y\left(s_{1}\right)-Y\left(s_{2}\right)\right], \quad \text { for } s_{1}, s_{2} \in \mathbb{S}
$$

which, in case of small differences between $s_{1}$ and $s_{2}$, can be interpreted as derivatives indicating the growth effect of a marginal increase in SF payments per GDP. 
Moodie and Stephens (2007) extend the GPS method to longitudinal data. Fryges and Wagner (2008) apply the GPS method to a panel of firms and evaluate the effect of export intensity on productivity growth simply by including time dummies into the conditioning set $X$ of the GPS. We follow this approach. To be more precise, we explain the response of real GDP growth from $t-1$ to $t+2$ by the ratio of SF payments and GDP in $t$, with $t=1999, \ldots, 2003 .{ }^{3}$ In accordance with Hirano and Imbens (2004), the associated standard errors are bootstrapped in order to account for the "generated regressor" problem. The bootstrap procedure includes all three steps described above.

\section{Data}

We use the SF data described in detail in Mohl and Hagen (2008). As the European Commission has only published regional SF payments for the period 1995-1999 (European Commission, 1996a,b, 1997, 1998, 1999, 2000), it additionally comprises the SF payments of the last Financial Perspective 2000-2006. The latter were recalled at the European Commission in Brussels and have, to the best of our knowledge, only been analyzed by Mohl and Hagen (2008) as yet. It has to be taken into account that the remaining payments from the previous Financial Perspective 1994-1999 are excluded, as this dataset is limited to the SF payments of the period 2000-2006. In order to avoid an underestimation of the total amount of European SF, we allocate those commitments from the Financial Perspective 1994-1999 that have not been paid out by 1999 to the years 2000 and 2001. In doing so, we calculate the residual amount of SF by subtracting the aggregated payments 1994-1999 from the aggregated commitments 1994-1999. Assuming that all commitments finally lead to payments and taking into account the $\mathrm{N}+2$ rule (see Footnote 2), we allocate the remaining amount at a rate of 2:1 to the years 2000 and 2001, respectively.

In our analysis, we concentrate on the total regional SF payments. These

$3 \quad$ Alternatively, we use a cross-sectional approach where the impact of the total structural funds payments between 2000 and 2004 (relative to GDP) on the growth rates between 1999 and 2005 is estimated. The results are similar. 
can be split up into three different Objectives, representing the key priorities of Cohesion Policy as defined by the European Commission in the Financial Perspective 2000-2006. Almost two-thirds of the structural funds are spent for Objective 1 payments, which are to promote development in less prosperous regions. The remaining part is spent fairly equally on regions in structural decline (Objective 2) and on support for education and employment polices. ${ }^{4}$ Note that there is a clear-cut definition concerning which regions qualify as an Objective 1 receiver (regional GDP has to be lower than $75 \%$ of the EU average), while a strict definition is missing in the case of the latter two Objectives. Multi-regional programs located at the national level (e.g., SF payments for national education systems) are not taken into consideration. In order to give an overview of the distribution of SF payments, Figure 1 displays the quantile map of SF payments within Europe. The darker the area, the higher the relative share of SF for the respective region. Figure 1 shows that the highest relative transfers go to Portugal, Spain, Greece, Eastern Germany and Ireland, while the benefits of Denmark, the southern parts of Sweden and of Germany and the northern part of Italy are rather small.

Figure 2 shows a scatter plot of our outcome variable and the treatment variable for $\mathbb{S}=[0.001 \%, 3.4 \%]$. The relationship is highlighted by a nonparametric (bivariate locally weighted) regression line, suggesting a slightly positive correlation between GDP growth and SF payments. Furthermore, it seems of particular interest that most regions receive SF payments that amount to less than $1 \%$ of GDP.

Apart from the SF variable, all other variables are from the Regio database by Eurostat. Due to recent modifications in the accounting standards (from the European System of Accounting (ESA) 1979 to ESA 1995), we only use variables available in ESA 1995. The complete list of regions and NUTS codes used in the following analysis are listed in the appendix.

$4 \quad$ Note that these Objectives in 2000-2006 consisted of two Objectives in the Financial Perspective 1994-1999. Objective 6 (1994-1999) became part of Objective 1 (2000-2006), Objective 5b (1994-1999) became part of Objective 2 (2000-2006) and Objective 4 (1994-1999) became part of Objective 3 (2000-2006). 
Figure 1: Quantile map, ln of SF Payments per Nominal GDP, 1995-2005

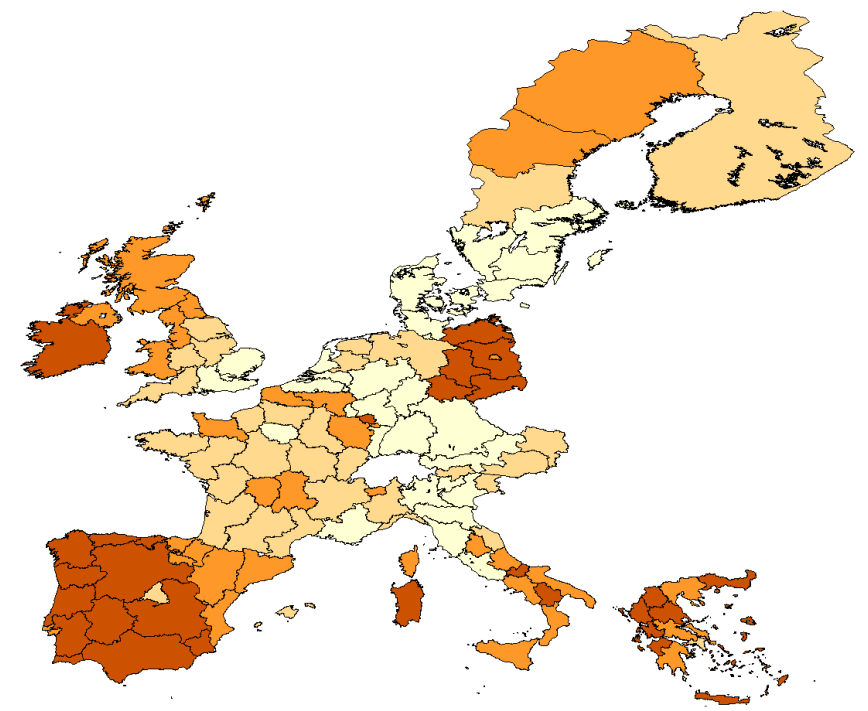

Source: Own illustration. The darker the area the wealthier is the region compared to the EU-15 average.

Figure 2: Growth of Real GDP per Capita (PPP) in \% and SF Payments per GDP in \%

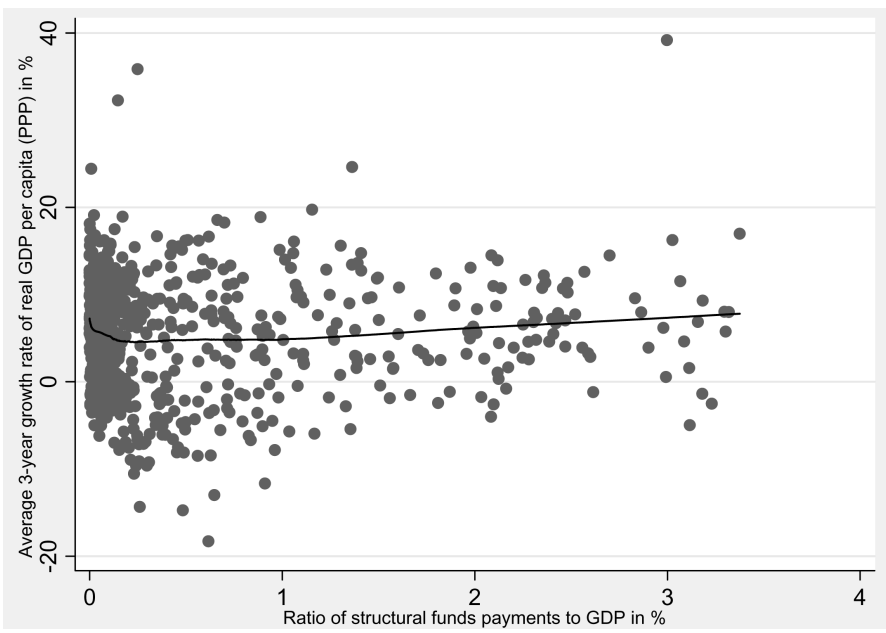

Source: Own illustration. Regions' GDP growth rate from $t-1$ to $t+3$ given the SF payments in $t$.

\section{Specification and Estimation of the GPS}

In order to justify the weak unconfoundedness assumption, the vector $X$ should consist of all variables simultaneously affecting the treatment variable 
(dose) and the outcome variable (response). Hence, it is crucial to include both the criteria for the allocation of funds and the mechanisms affecting the regions ability to call up and to co-finance the payments into the GPS specification.

In our application, the conditioning set $X$ is limited by data availability at the NUTS level. We condition on the levels of the outcome variable (real GDP per capita in PPP) prior to the treatment $(t-1$ up to $t-3$ ) in order to balance pre-treatment differences in the regions' initial position. Furthermore, the variable "ratio of GDP per capita (PPP) to EU average" is included, as it is the central criterion for qualifying as a so-called "Objective 1 "-region and receiving the highest transfers. Since areas with very low population densities, such as Sweden and Finland, also qualify for "Objective 1 "-funding, the population density is included in the estimation of the GPS. ${ }^{5}$

Moreover, industrial areas can qualify for "Objective 2"-status if unemployment is above EU average, if the employment share in the industrial sectors is above EU aver-age, or if industrial employment is declining. For this reason, we include variables describing the employment structure (e.g., the ratio of industrial employment to total employment), as well as the unemployment rate. In order to capture the differences in the regional labor markets and in order to take the ultimate SF funding aim of reducing longterm unemployment into account, the ratio of long-term unemployment to total unemployment is included in the specification. Note that the unemployment rate is included both lagged $(t-2$ and $t-3)$ and squared, since this setup leads to a better fit in terms of adjusted $R^{2}$, Akaike's information criterion (AIC) and Schwarz Information Criterion (SIC). Finally, country dummies are considered, to account for country-specific particularities in the allocation and the use of the funding. The descriptive statistics of our variables can be found in Table 1 .

$5 \quad$ Note that variables only affecting the outcome variable but not the treatment level are irrelevant for propensity score approaches. Furthermore, variables only affecting the treatment level but not the outcome variable could be instrumental variables. If instrumental variables were available, it would be possible to take endogeneity (also called "selection on unobservables") into account. 
Table 1: Descriptive Statistics of the Estimation Sample

\begin{tabular}{|c|c|c|c|c|}
\hline & Mean & Std. Dev. & Min. & Max. \\
\hline Ratio of SF to nominal GDP (in \%) & 1.18 & 2.54 & 0.00 & 25.77 \\
\hline Real GDP per capita (PPP) in Euro (t-1) & $22,180.3$ & $6,131.2$ & $11,622.2$ & $5,3929.5$ \\
\hline $\begin{array}{l}\text { Ratio of GDP per capita (PPP) to EU } \\
\text { average (t-3) }\end{array}$ & 107.56 & 29.14 & 58.70 & 248.30 \\
\hline Unemployment rate $(\mathrm{t}-2)$ & 0.08 & 0.05 & 0.01 & 0.27 \\
\hline $\begin{array}{l}\text { Ratio of industry employment to total } \\
\text { employment }(\mathrm{t}-2)\end{array}$ & 0.28 & 0.07 & 0.12 & 0.48 \\
\hline $\begin{array}{l}\text { Ratio of agriculture employment to total } \\
\text { employment }(\mathrm{t}-2)\end{array}$ & 0.08 & 0.08 & 0.00 & 0.43 \\
\hline $\begin{array}{l}\text { Ratio of long-term unemployed to total } \\
\text { unemployment }(\mathrm{t}-2)\end{array}$ & 0.45 & 0.13 & 0.07 & 0.79 \\
\hline Population density (t-3) & 230.89 & 567.09 & 1.00 & $5,927.90$ \\
\hline
\end{tabular}

The final specification in Table 2 is found after testing how the best fit (adjusted $R^{2}, \mathrm{AIC}, \mathrm{SIC}$ ) and the best balancing results (see below) can be achieved. An adjusted $R^{2}$ of 0.57 may indicate that many important variables are accounted for. Note that the estimated coefficients of single variables cannot be interpreted, due to multicollinearity. For this reason, the bottom of Table 2 reports the results of joint tests.

A fundamental question is whether conditional on these $X$ variables, exogeneity of the treatment can be assumed. Important variables summarizing differences between regions, such as human capital, are missing. Hence, we have to assume that by conditioning on the available observed variables, unobserved variables are also captured, as they are correlated with the observed variables. ${ }^{6}$

A last safeguard against an endogeneity bias may be the fact that our dependent variable is first-differenced over time (growth of GDP instead of level of GDP) which eliminates time-constant heterogeneity in initial positions between regions.

As noted by Flores-Lagunes, Gonzalez, and Neuman (2007) as well as by Imai and van Dijk (2004), one approach to check the balancing property of the GPS (the balance of the pre-treatment covariates $X$ ) is to run regressions of each covariate on the treatment variable $S$ and the estimated GPS $\hat{R}$.

$6 \quad$ Unless plausible instrumental variables are available, there is no way to test the weak unconfoundedness assumption directly. 
Table 2: Parameter Estimates of the Generalised Propensity Score (OLS)

\begin{tabular}{|c|c|c|}
\hline & Coef. & t-stat. \\
\hline Real GDP per capita (PPP) (t-1) / 1,000 & -0.625 & -5.42 \\
\hline Real GDP per capita (PPP) (t-2) / 1,000 & 0.427 & 2.73 \\
\hline Real GDP per capita (PPP) (t-3) / 1,000 & -0.302 & -1.13 \\
\hline Ratio of GDP per capita (PPP) to EU average (t-3) & 0.120 & 1.98 \\
\hline Ratio of GDP per capita (PPP) to EU average (t-4) & -0.030 & -1.14 \\
\hline ln unemployment rate $(\mathrm{t}-2)$ & 8.708 & 2.78 \\
\hline ln unemployment rate $(\mathrm{t}-3)$ & -9.556 & -2.99 \\
\hline ln unemployment rate (t-2) squared & 2.215 & 2.14 \\
\hline ln unemployment rate (t-3) squared & -2.383 & -2.20 \\
\hline Ratio of long-term unemployed (t-3) & -0.457 & -0.48 \\
\hline ln population density $(\mathrm{t}-3)$ & -0.019 & -0.24 \\
\hline ln proportion of industry employment (t-2) & -0.282 & -0.22 \\
\hline ln proportion of agriculture employment ( $\mathrm{t}-2$ ) & 0.162 & 0.36 \\
\hline ln proportion of industry employment (t-3) & -0.866 & -0.67 \\
\hline ln proportion of agriculture employment (t-3) & -0.040 & -0.09 \\
\hline \multicolumn{3}{|l|}{ Country dummies (Base: Belgium): } \\
\hline Denmark & -0.421 & 0.66 \\
\hline Germany & -0.133 & 0.82 \\
\hline Greece & 3.836 & 0.00 \\
\hline Spain & 2.005 & 0.01 \\
\hline France & -0.429 & 0.46 \\
\hline Ireland & 1.829 & 0.18 \\
\hline Italy & 0.060 & 0.92 \\
\hline Luxembourg & 1.504 & 0.18 \\
\hline Netherlands & 0.035 & 0.96 \\
\hline Austria & -0.392 & 0.59 \\
\hline Portugal & 0.940 & 0.23 \\
\hline Finland & -0.046 & 0.97 \\
\hline Sweden & -0.406 & 0.55 \\
\hline UK & -0.146 & 0.81 \\
\hline \multicolumn{3}{|l|}{ Time dummies (Base: 1999): } \\
\hline 2000 & 1.764 & 6.23 \\
\hline 2001 & 2.622 & 6.36 \\
\hline 2002 & 1.909 & 3.32 \\
\hline 2003 & 2.199 & 2.69 \\
\hline Constant & -1.575 & -0.80 \\
\hline \multicolumn{3}{|l|}{ Joint tests: } \\
\hline F-stat. p-value (GDP variables) & & 0.0000 \\
\hline F-stat. p-value (unemployment and population variables) & & 0.0000 \\
\hline F-stat. p-value (employment variables) & & 0.0218 \\
\hline F-stat. p-value (country dummies) & & 0.0000 \\
\hline F-stat. p-value (time dummies) & & 0.0000 \\
\hline Number of regions & & 122 \\
\hline Number of observations & & 578 \\
\hline Adjusted R-squared & & 0.57 \\
\hline
\end{tabular}


If a certain covariate is balanced, the treatment variable should have no predictive power for the particular covariate conditional on the estimated GPS. By comparing the estimated t-statistics of the coefficients ("adjusted t-stat.") to the corresponding t-statistic of the coefficient of a regression that does not include the estimated GPS ("unadjusted t-stat."), one can obtain an idea about the degree of balancing generated by the GPS. For each continuous covariate we use OLS; for each binary variable we apply a logit model.

The results of this exercise are shown in Table 3. In almost all cases the t-statistics are significantly reduced when switching from "unadjusted" to "adjusted". Only in the case of the unemployment rate and the ratio of industry employment do the t-statistics continue to indicate statistically significant coefficients. For the ratio of long-term unemployed in total unemployment, the figures even show an increase of the t-statistics. Most importantly, however, the outcome variable "real GDP per capita (in PPP)" seems to be perfectly balanced prior to the treatment, which can be interpreted as a kind of "pre-program test" in the sense of Heckman and Hotz (1989). Since our approach turns out to be suitable for balancing pre-treatment differences

Table 3: Tests of the Balancing Property: t-statistics for the Coefficients of the Treatment Variable

\begin{tabular}{lrr}
\hline Variable & $\begin{array}{r}\text { Unadjusted } \\
\text { t-stat. }\end{array}$ & $\begin{array}{r}\text { Adjusted } \\
\text { t-stat. }\end{array}$ \\
\hline Real GDP per capita (PPP) (t-1) / 1,000 & 6.25 & 0.83 \\
Real GDP per capita (PPP) (t-2) / 1,000 & 6.44 & 0.95 \\
Real GDP per capita (PPP) (t-3) / 1,000 & 6.40 & 1.02 \\
Ratio of GDP per capita (PPP) to EU average (t-3) & 6.45 & 0.97 \\
Ratio of GDP per capita (PPP) to EU average (t-4) & 6.44 & 0.97 \\
ln unemployment rate (t-2) & 6.92 & 2.96 \\
Ratio of long-term unemployed (t-3) & 6.78 & 12.40 \\
ln ratio of industry employment (t-2) & -12.84 & -7.34 \\
ln ratio of agriculture employment (t-2) & -5.94 & 1.50 \\
ln population density (t-3) & 7.52 & 0.37 \\
Time dummies (Base: 1999): & & \\
2000 & -2.55 & 0.16 \\
2001 & -1.94 & 1.16 \\
2002 & -4.38 & -3.01 \\
2003 & -4.75 & -3.03 \\
\hline
\end{tabular}


in real GDP per capita, we can be optimistic that the unconfoundedness assumption may be fulfilled.

As discussed above, the outcome variable $Y$ is the average three-year GDP growth rate (real GDP per capita (in PPP)) in percent which is explained by the ratio of SF payments to GDP (in percent). The estimation results of the second step (equation 3) are shown in Table 4. Note that the estimated coefficients do not have any causal interpretation. According to Hirano and Imbens (2004), a test on whether all coefficients involving the GPS are equal to zero in this regression can be interpreted as a test on whether the covariates introduce any bias. Joint tests can be found at the bottom of Table 4 . They indicate a rejection of the hypothesis that the coefficients are jointly zero. Hence conditioning on the covariates (via the GPS) is necessary.

Table 4: Estimated Parameters of the Conditional Distribution of GDP Growth Given SF Payments (in \% GDP) and the Estimated GPS (OLS)

\begin{tabular}{lrr}
\hline & Coef. & t-stat. \\
\hline S / 1,000 & 6.387 & 1.68 \\
$S^{2} / 1,000$ & -0.145 & -0.78 \\
$\hat{R}$ & 1.184 & 1.82 \\
$\hat{R}^{2}$ & -6.455 & -2.15 \\
$\hat{R} \cdot S / 1,000$ & -2.283 & -0.68 \\
Constant & 0.004 & 0.12 \\
\hline Joint tests: & & \\
F-stat. p-value $\left(\hat{R}, \hat{R}^{2}\right)$ & & 0.0342 \\
F-stat. p-value $\left(\hat{R}, \hat{R}^{2}, \hat{R} \cdot S\right)$ & & 0.0672 \\
\hline Number of observations & & 578 \\
\hline
\end{tabular}

\section{Estimation of the Dose-Response Function}

In order to reveal the causal relationship of interest, a dose-response function is estimated via equation (4) and is displayed in Figure 3. The point estimates, as well as the corresponding simulated $95 \%$ confidence interval are shown. The shape of the confidence intervals can be explained by the fact that the number of observations is reduced with an increasing dose. Furthermore, a "covariate-adjusted non-participants" mean growth rate (3.8\%) 
Figure 3: Estimated Dose-Response Function: Growth of Real GDP per Capita (PPP) in \% and 95\% Confidence Interval

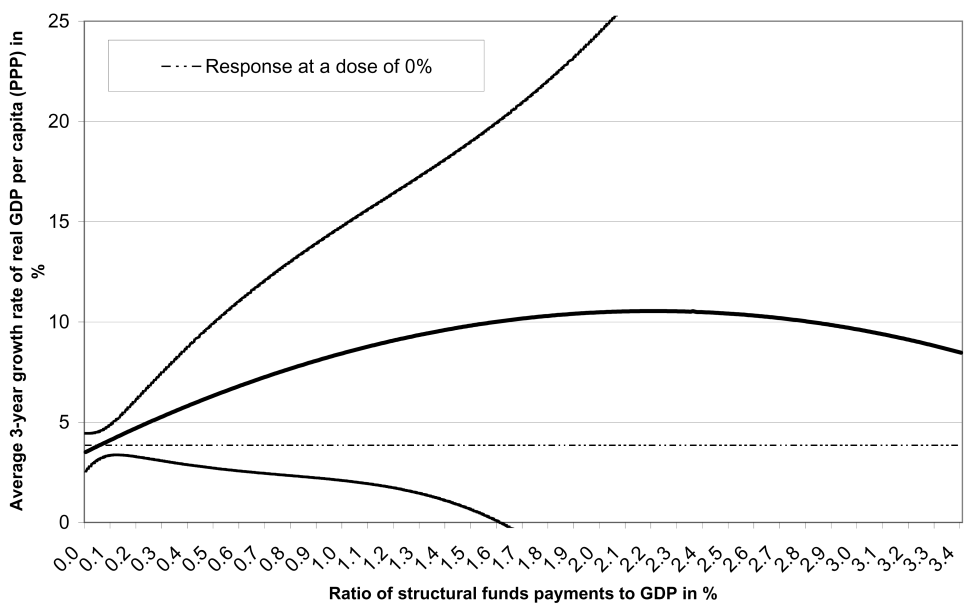

Notes:

Solid line: Estimated conditional expectation of regions' GDP growth rate from $t-1$ to $t+3$ given the SF payments in $t$ and the estimated generalized propensity score.

Dotted lines: Simulated $95 \%$ confidence interval, using the $5^{\text {th }}$ and $95^{\text {th }}$ percentiles of the bootstrap distribution (5,000 replications).

Source: Own illustration.

is shown as a horizontal line ("response at a dose of $0 \%$ "). ${ }^{7}$ This can be interpreted as an estimate of the average growth rate of the treated regions if they did not receive any SF payments.

The point estimates indicate a positive relationship: At least up to a dose of approximately $2.1 \%$, the growth rate rises with an increasing dose. However, as documented by the confidence intervals, the relationship is far from being statistically significantly different from zero (at the $5 \%$, as well

$7 \quad$ Following Flores-Lagunes, Gonzalez, and Neuman (2007), we estimate the "covariateadjusted non-participants" mean growth rate as follows. First, we estimate a linear model for the growth rate as a function of all conditioning variables in $X$ based on regions receiving or not receiving SF payments. Second, we predict the growth rate for the sample of the regions receiving SF payments, assuming $S=0$. The mean of this prediction is the "covariate-adjusted non-participants" mean growth rate. Since the results of the dose-response function are very clearly statistically insignificant, we do not show the confidence interval of this estimate, in order to ensure clarity of the figure. 
as the $10 \%^{8}$ level). Furthermore, it is not statistically significantly different from the growth rate at a dose of zero $(3.8 \%)$.

Figure 4 shows the derivatives of the dose-response function, which indicate the increase in the growth rate in percentage points resulting from a marginal increase in the dose. We see diminishing returns which are, however, once again not statistically significantly different from zero. In other words, with regard to economic growth, it does not matter which "dose" of SF payments a region receives.

Figure 4: Estimated Derivatives and 95\% Confidence Interval

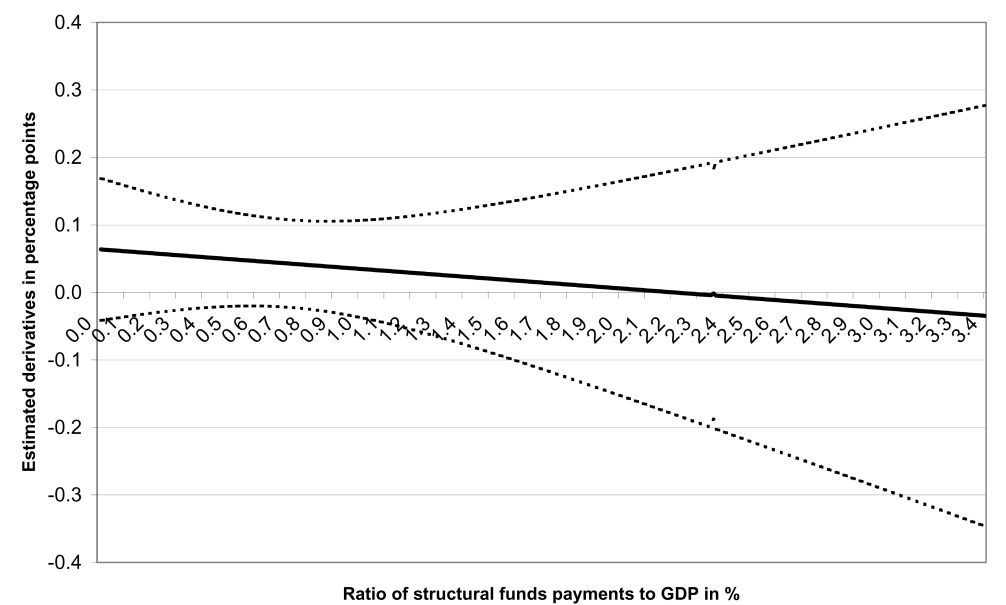

Notes:

Solid line: Estimated conditional expectation of regions' GDP growth rate from $t-1$ to $t+3$ given the SF payments in $t$ and the estimated generalized propensity score.

Dotted lines: Simulated $95 \%$ confidence interval, using the $5^{\text {th }}$ and $95^{\text {th }}$ percentiles of the bootstrap distribution (5,000 replications).

Source: Own illustration.

\section{Conclusion}

The aim of this paper is to evaluate the growth effects of SF payments at the regional level. In contrast to the existing literature, the focus lies on avoiding functional form assumptions to a large extent. As a consequence, we apply a continuous treatment effects model to estimate a dose-response function.

8 The $90 \%$ confidence interval is not shown. 
In doing so, we employ the dataset by Mohl and Hagen (2008) consisting of a sample of 122 NUTS-1 and NUTS-2 regions, which comprises, for the first time, structural funds payments of the Financial Perspective 2000-2006.

Statistical tests suggest that the approach is suitable for balancing pretreatment differences between regions to a large extent, implying that we may be able to yield an unbiased estimate of the regional growth effect of structural funds payments. At any rate, the method applied may be a promising approach for future research evaluating regional policy.

Our results indicate that structural funds payments have a positive, but not statistically significant, impact on the European regions' growth rates. This implies that it does not matter which "dose" of SF payments a region receives. This result is well in line with previous studies using parametric approaches that indicate rather mixed effects of the Cohesion Policy.

In order to raise the plausibility of the so-called SUTVA, which rules out regional spillovers, a combination of the methodology of the generalized propensity score and spatial econometric techniques may be fruitful. However, this methodological innovation is left for future research.

\section{Acknowledgements}

Special thanks go to Jose Madeira and Christian Weise (both European Commission) for their helpful support in acquiring the EU structural funds payments for 2000-2006. Moreover, we would like to thank Florian Mayer for his excellent research assistance. 


\section{A Construction of the dataset}

We follow Mohl and Hagen (2008) in the construction of the structural funds payments dataset. As structural funds payments are not available for all EU regions at the NUTS-2 level, our dataset consists of 122 NUTS-1 and NUTS-2 regions $^{9}$ (see Mohl and Hagen (2008) for a detailed description of the dataset). Here we do not consider the overseas regions of France (Départments d'outremer (fr9) consisting of Guadeloupe (fr91), Martinique (fr92), Guyane (fr93) and Réunion (fr94)), Portugal (Região Autónoma dos Açores (pt2, pt20), Região Autónoma da Madeira (pt3, pt30)), and Spain (Canarias (es7, es70)).

As a consequence, our dataset consists of 122 NUTS-1 and NUTS-2 regions with positive SF payments, which are listed in the following, including the abbreviations of the NUTS codes in brackets, in accordance with the classifications of the European Commission (2007).

Austria (3 NUTS-1 regions): Ostösterreich (at1), Südösterreich (at2), Westösterreich (at3);

Belgium (3 NUTS-1 regions): Région de Bruxelles-capitale (be1), Vlaams Gewest (be2), Région Wallonne (be3);

Denmark (1 NUTS-2 region): Denmark (dk);

Finland (2 NUTS-1 regions): Manner-Suomi (fi1), Åland (fi2);

France (22 NUTS-2 regions): Île de France (fr10), Champagne-Ardenne (fr21), Picardie (fr22), Haute-Normandie (fr23), Centre (fr24), Basse-Normandie (fr25), Bourgogne (fr26), Nord-Pas-de-Calais (fr30), Lorraine (fr41), Alsace (fr42), Franche-Comté (fr43), Pays-de-la-Loire (fr51), Bretagne (fr52), Poitou-Charentes (fr53), Aquitaine (fr61), Midi-Pyrénées (fr62), Limousin (fr63), Rhône-Alpes (fr71), Auvergne (fr72), Languedoc-Roussillon (fr81), Provence-Alpes-Côte d'Azur (fr82), Corse (fr83);

Germany (15 NUTS-1 regions): Baden-Württemberg (de1), Bayern (de2), Berlin (de3), Brandenburg (de4), Bremen (de5), Hamburg (de6), Hessen (de7), Mecklenburg-Vorpommern (de8), Niedersachsen (de9), Nordrhein-Westfalen (dea), Rheinland-Pfalz (deb), Sachsen (ded), Sachsen-Anhalt (dee), Schleswig-Holstein (def), Thüringen (deg);

$9 \quad$ The European Commission (2007) classifies the EU regions according to the "Nomenclature des unités territoriales statistiques" (NUTS) which refers to the country level (NUTS-0) and to three lower subdivisions (NUTS-1, NUTS-2 and NUTS-2) which are mainly classified according to the population size. 
Greece (13 NUTS-2 regions): Anatoliki Makedonia, Thraki (gr11), Kentriki Makedonia (gr12), Dytiki Makedonia (gr13), Thessalia (gr14), Ipeiros (gr21), Ionia Nisia (gr22), Dytiki Ellada (gr23), Sterea Ellada (gr24), Peloponnisos (gr25), Attiki (gr30), Voreio Aigaio (gr41), Notio Aigaio (gr42), Kriti (gr43);

Ireland (1 NUTS-1 region): Irland (ie);

Italy (19 NUTS-2 regions): Piemonte (itc1), Valle d'Aosta/Vallée d'Aoste (itc2), Liguria (itc3), Lombardia (itc4), Veneto (itd3), Friuli-Venezia Giulia (itd4), Emilia-Romagna (itd5), Toscana (ite1), Umbria (ite2), Marche (ite3), Lazio (ite4), Abruzzo (itf1), Molise (itf2), Campania (itf3), Puglia (itf4), Basilicata (itf5), Calabria (itf6), Sicilia (itg1), Sardegna (itg2);

Luxembourg (1 NUTS-2 region): Luxembourg (ie);

The Netherlands (4 NUTS-1 regions): Noord-Nederland (nl1), Oost-Nederland (nl2), West-Nederland (nl3), Zuid-Nederland (nl4);

Portugal (2 NUTS-2 regions): Norte (pt11), Algarve (pt15);

Spain (16 NUTS-2 regions): Galicia (es11), Principado de Asturias (es12), Cantabria (es13), País Vasco (es21), Comunidad Foral de Navarra (es22), La Rioja (es23), Aragón (es24), Comunidad de Madrid (es30), Castilla y León (es41), Castilla-La Mancha (es42), Extremadura (es43), Cataluña (es51), Comunidad de Valenciana (es52), Illes Balears (es53), Andalucía (es61), Región de Murcia (es62);

Sweden (8 NUTS-2 regions): Stockholm (se11), Östra Mellansverige (se12), Småland med öarna (se021), Sydsverige (se22), Västsverige (se23), Norra Mellansverige (se31), Mellersta Norrland (se32), Övre Norrland (se33);

UK (12 NUTS-1 regions): North East (ukc), North West (ukd), Yorkshire and the Humber (uke), East Midlands (ukf), West Midlands (ukg), East of England (ukh), London (uki), South East (ukj), South West (ukk), Wales (ukl), Scotland (ukm), Northern Ireland (ukn). 


\section{References}

Arellano, M., AND S. Bond (1991): "Some tests of specification for panel data: Monte Carlo evidence and an application to employment equations," The Review of Economic Studies, 58, 277-297.

BÄHR, C. (2008): "How does sub-national autonomy affect the effectiveness of structural funds," Kyklos, 61(1), 3-18.

Beugelsdijk, M., ANd S. EiJfFinger (2005): "The effectiveness of structural policy in the European Union: An empirical analysis for the EU-15 in 19952001," Journal of Common Market Studies, 40, 37-51.

Bia, M., AND A. Mattei (2007): "Application of the Generalized Propensity Score. Evaluation of public contributions to Piedmont enterprises," Working Paper of the Department of Public Policy and Public Choice (POLIS), No. 89.

Blundell, R., AND S. Bond (1998): "Initial conditions and moment restrictions in dynamic panel data models," Journal of Econometrics, 87, 115-143.

Dall'erba, S., And J. Le Gallo (2008): "Regional convergence and the impact of European structural funds 1989-1999: A spatial econometric analysis," Papers in Regional Science, 82(2), 219-244.

Durlauf, S. N., AND D. Quah (1999): "The new empirics of economic growth," in Handbook of Macroeconomics, ed. by J. Taylor, and M. Woodford, vol. 1. North Holland, Amsterdam.

Ederveen, S., H. de Groot, and R. Nahuis (2006): "Fertile soil for structural funds? A panel data analysis of the conditional effectiveness of European cohesion policy," Kyklos, 59, 17-42.

Esposti, R., And S. Bussoletti (2008): "Impact of Objective 1 funds on regional growth convergence in the European Union: A panel-data approach," Regional Studies, 42(2), 159-173.

European Commission (1996a): Seventh annual report on the structural funds 1995. Brussels.

(1996b): Sixth annual report on the structural funds 1994. Brussels.

(1997): Eighth annual report on the structural funds 1996. Brussels.

(1998): Ninth annual report on the structural funds 199\%. Brussels.

(1999): Tenth annual report on the structural funds 1998. Brussels.

(2000): Report from the Commission. 11th annual report on the structural funds 1999. Brussels.

(2007): "Commission Regulation (EC) No 105/2007," Official Journal of the European Union, L 39. 
Flores, C. (2004): "Estimation of dose-response functions and optimal doses with a continuous treatment," Job Market Paper, University of California, Berkeley.

Flores-Lagunes, A., A. Gonzalez, and T. Neuman (2007): "Estimating the effects of length of exposure to a training program: The case of job corps," IZA Discussion Paper, 2846.

FRYGes, H., AND J. WAGner (2008): "Exports and productivity growth - first evidence from a continuous treatment approach," Review of World Economics, 144(4), 694-721.

Hagen, T., And P. Mohl (2008): "How does EU Cohesion Policy work? Evaluating the effects of Cohesion Policy with regard to various outcome variables," mimeo.

Heckman, J. J., AND V. J. Hotz (1989): "Choosing among nonexperimental methods for estimating the impact of social programs: The case of manpower training," Journal of the American Statistical Association, 84, 862-874.

Hirano, K., And G. W. Imbens (2004): "The propensity score with continuous treatments," in Applied Bayesian Modeling and Causal Inference from Incomplete-Data Perspectives, ed. by A. Gelman, and X.-L. Meng, pp. 73-84. John Wiley and Sons, West Sussex.

ImAI, K., AND D. A. VAN DiJK (2004): "Causal inference with general treatment regimes: Generalizing the propensity score," Journal of the American Statistical Association, 99, 854-866.

ImBENS, G. (2004): "Nonparametric estimation of average treatment effects under exogeneity: A review," Review of Economics and Statistics, 86, 4-29.

IslAm, N. (2003): "What have we learnt from the convergence debate?, Journal of Economic Surveys, 17, 309-362.

Kluve, J., H. Schneider, A. Uhlendorff, And Z. Zhao (2007): "Evaluating continuous training programs using the generalized propensity score," Ruhr Economic Papers, 35.

Mohl, P., And T. Hagen (2008): "Does EU Cohesion Policy promote growth? Evidence from regional data and alternative econometric approaches," $Z E W$ Discussion Paper, 08-086.

Moodie, E. E. M., And D. A. Stephens (2007): "Estimation of dose-Response functions for longitudinal data," COBRA Preprint Series, 32.

Percoco, M. (2005): "The impact of structural funds on the Italian Mezzogiorno, 1994-1999," Région et Developpement, 21, 141-152.

Rubin, D. (1980): "Discussion of "Randomization analysis of experimental data: The Fisher randomization test" (by D. Basu)," Journal of American Statistical Association, 75, 591-93. 